\title{
Encouraging minority scientists
}

\section{The research community needs to increase the number of minority students who choose scientific research careers.}

n n what has become known as his 'tough love' speech given at the 100th anniversary convention of the National Association for the Advancement of Colored People, President Barack Obama urged black students to aspire to be "scientists and engineers, doctors and teachers," stressing that "education is essential." However, the hurdles faced by minority students striving to succeed in pursuit of a science career extend beyond "turning off the Xboxes." As with many discussions of race or ethnicity, historical legacy has limited equality of opportunity and unfortunately many students still encounter difficulties that make the thought of attending college merely a dream. The focus here, however, is not on early education programs but instead is on those students who have entered undergraduate schools and beyond and therefore are likely to consider scientific research as a career.

Black and Hispanic Americans compose roughly one third of the US population, yet the percentage of graduate degrees earned by members of these minorities is much less than $30 \%$. This proportional disparity is called 'under-representation'. In the United States, under-represented minorities in science and engineering programs include blacks, Hispanics and Native Americans. According to "Science and Engineering Indicators 2008," published by the National Science Foundation (http://www.nsf.gov/ statistics/seind08/), under-represented minority students earned only $6 \%$ of all science or engineering $\mathrm{PhD}$ degrees awarded in the United States in 2006. The frequency is even less for those who go on to pursue additional postdoctoral training, which today is an essential step for consideration for a faculty position in the biomedical sciences. Far fewer minorities are tenured faculty or on the tenure track at major research universities, according to a 2007 report by Donna Nelson and colleagues (http://cheminfo.ou.edu/ djn/diversity/Faculty_Tables_FY07/07Report.pdf). Only 168 people of a minority background were listed as faculty members in biological science departments of the top 50 research institutions in the United States as of 2007. Thus, at every step in career advancement, minority scientists are under-represented. Despite the fact that more minority students enter undergraduate programs today than nearly 25 years ago, the dearth of minority representation in faculty and mentoring positions is a discouraging sign and perpetuates the cycle of under-representation, according to Nelson's report.

This situation must change. So how can the research community encourage more minority students to pursue a research career? Understanding and reducing the hurdles faced by minority students and increasing their exposure to research environments is needed to increase graduate student diversity in the future. Many anecdotal stories have suggested that exposing students to hands-on research and access to more senior investigators motivates their interest in pursuing a research career (http://chronicle. com/article/Summer-Programs-Heighten/47459/). Such experiences illuminate the multitude of possibilities that exist and provide realistic expectations for what such a career entails. However, students also need to know that the research community welcomes racial diversity, which can be achieved by an increase in the 'visibility' of minority scientists; that is, they must see 'there are people like me with a $\mathrm{PhD}$ '. Increasing the number of minority postdoctoral fellows, recruiting more minorities to faculty positions and promoting those junior faculty to more senior positions would contribute to that goal.

The National Institute of General Medical Sciences (NIGMS) of the US National Institute of Health has initiated programs to increase student diversity in the biomedical and behavioral sciences, targeting under-represented minority students. NIGMS is now soliciting institutional applications for the Initiative for Maximizing Student Development to develop programs at research-intensive universities aimed at exposing more students of all races to research settings and to provide compensation to help retain those students who might otherwise face financial hardships, so they can continue their research endeavors.

The American Association of Immunologists has established a Minority Affairs Committee to foster networking and mentoring programs for minority students and junior faculty. More senior faculty members should identify interested students and alert them to these professional resources. The American Scociety for Microbiology, in conjunction with NIGMS and other scientific societies, sponsors the Annual Biomedical Research Conference for Minority Students, to be held this year in Phoenix, Arizona (4-7 November). This conference provides a forum for minority undergraduates and graduate students to present their own research and facilitates their exposure to graduate school programs and postdoctoral opportunities. Students can also network with more senior investigators to compare their experiences and expectations. Such 'critical mass' networking interactions help to inspire confidence and can continue long after the attendees have returned home.

The Keystone Symposia have also initiated a 'Diversity in Life Science Program' to increase the participation of minority scientists at Keystone conferences. Conference organizers are encouraged to identify and invite more minority scientists to present their work in workshops and plenary sessions. Presenting work to a larger international audience can often lead to collaborations with other researchers, which should also be encouraged.

As the US population becomes less 'white dominated', more minority workers will enter the workforce. This scenario is no less true for scientific research, especially as a substantial number of white male faculty members prepare to retire in the next decade. Thus, the training of tomorrow's scientists and faculty must begin today. To achieve this, faculty chairs and administrators must identify those hurdles that might now preclude the career development of under-represented minorities on their campuses and take steps to ensure their education programs are sufficiently rigorous to train competitive minority scientists. There is no time to waste.

Corrected 18 September 2009 


\section{Erratum: "Encouraging minority scientists"}

Nat. Immunol. 10, 927 (2009); corrected after print 18 September 2009

In the version of this article initially published, a cosponsor of the Annual Biomedical Research Conference for Minority Students is identified incorrectly as the American Association for the Advancement of Science. It should be the American Society for Microbiology. The error has been corrected in the HTML and PDF versions of the article. 